\title{
An investigation of perceived body aesthetics and its contribution to the empowerment of marketing strategies for sporting goods
}

Received (in revised form): 25th February, 2007

\section{George S. Spais}

has a PhD from Panteion University of Social and Political Sciences, Greece and is Adjunct Assistant Professor of Marketing at University of Peloponnese (Greece). He has published works on marketing communications, strategic marketing and marketing education. His work has been published in international academic journals such as the Journal of Strategic Marketing, the Journal of Korean Academy of Marketing Science, the Journal of Financial Services Marketing, the Journal of Business Case Studies, the Journal of Database Marketing and Customer Strategy Management and elsewhere. His research interests are focused on strategic marketing, marketing communications and marketing education. He serves as a regional editor (Continental Europe) for the International Electronic Journal for Leadership in Learning.

\section{Pantelis D. Konstantinakos}

has a PhD from University of Thessaly, Greece and is Assistant Professor of Sociology at University of Peloponnese (Greece). His extensive research activity includes a series of works in sports sociology and sport science, which has been presented in international academic journals such as Sport and Science, La Educazione Fisica e Sport nella Scuola and elsewhere. His research interests are focused on the fields of sport leisure and recreation, sport leisure and tourism, physical culture and tourism, and sport leisure and culture.

Keywords body aesthetics, marketing strategies, sporting goods, students, market segmentation criterion

\begin{abstract}
The multiple linear regression method was used to model the relationship among influence of body aesthetics, perceived benefit of body aesthetics and influence of media to perceived body aesthetics. Four alternative models were developed in order to lead to a better understanding of the significance of others' opinions to the perceived body aesthetics. We address the core research themes of our study using a survey. The research hypotheses aim to test students' attitudes regarding to body aesthetics, in order to understand this modern raising issue (as an effective psychographic segmentation criterion) in the planning of modern marketing strategies of sporting goods. For this reason, we investigate the effect of some of the general behavioural descriptors regarding to social class. The convenience sample included 401 students (interested in sporting activities) from three different Greek universities (eight departments). Our intention is to reach students with different experiences, attitudes, educational and family background. Data were collected by means of face-to-face interviews during the ten-week period. According to the research results, we accept the fourth hypothesis $\left(\mathrm{H}_{4}\right)$, which means that model 4 better predicts perceived body aesthetics. The findings of this study have some interesting implications not only for marketing managers of sporting goods but also for policy-makers.

Journal of Targeting, Measurement and Analysis for Marketing (2007) 15, 158-169. doi:10.1057/palgrave.jt.5750041
\end{abstract}

Correspondence: George S. Spais, Regional Editor, IEJLL, Adjunct Assistant Professor, Department of Sport Management, University of Peloponnese, Lysandrou Street 3-23100, Sparti, Greece.

Tel: +30-27310-89.664;

E-mail: gspais@uop.gr

\section{INTRODUCTION}

The cultural implications of body aesthetics are prominent in every culture and have a strong influence on the way men and women are 
perceived. Across the world, different cultural perceptions uphold an ideal of beauty that is linked to sexual appeal and social status. Our study will focus on the examination of the construct of perceived body aesthetics as linked to some of the general behavioural descriptor of social class.

Body dissatisfaction is important because of its established association (eg Silverstein and Perlik ${ }^{1}$ ) with depression, low self-esteem and disordered eating. Much of the research on body dissatisfaction and particularly research on disordered eating, has focused on the effect of the extremely slender ideal female body types found in Western Europe and North America. By the late 1960s, the voluptuous 'sweater girls' of the 1940s and 1950s had been replaced by very slender, almost boy-like, fashion models. ${ }^{2}$ Objective measures of cultural beauty ideals such as Playboy centrefolds and beauty pageant winners have confirmed this trend. ${ }^{3-5}$ As many authors have noted (eg Garner et al., ${ }^{3}$ Rodin et al. ${ }^{6}$ ), for most women this extremely slender body type is both unhealthy and unobtainable. It is thus not surprising that adoption of the thin body ideal has been paralleled by women's decreasing satisfaction with their bodies. ${ }^{7}$ As Brumberg $^{8}$ and many others have noted, it seems paradoxical that at the very time when social changes have greatly increased available roles and opportunities for women, social expectations of female body types have become increasingly rigid and unrealistic, deviations from these expectations have produced increasingly negative social reactions and self-evaluations, and large numbers, probably the majority, of young Western women have learned to judge their bodies by unhealthy, unrealistic and unobtainable standards.

The rapid decline of socialism and the adoption of market economies have produced enormous social and political changes in Eastern Europe. Some authors have argued that the socialist system, with its emphases on egalitarianism, rejection of traditional views of femininity and lack of objectification of female bodies, protected women from excessive concerns with physical appearance, the tyranny of the thin body ideal and disordered eating. ${ }^{1,9,10}$ Even if this assessment is correct, these protections were lost with the decline of the socialist system and the development of market economies. It seems very likely that the loss of these protections, combined with the enormous social and economic stresses associated with the rapid introduction of Western values and the rapidly changing roles of women, have contributed to the marked increase in body dissatisfaction and disordered eating in Eastern Europe. ${ }^{10-13}$

\section{Post-modernism and body aesthetics}

Post-modernism, for Jameson ${ }^{14}$ (p. xii), is 'not the cultural dominant of a wholly new social order ..., but only the reflex and the concomitant of yet another systemic modification of capitalism itself'. This modification has resulted in postmodern capitalism, in Jameson's view the purest form of capital yet to emerge. Everything now has become a commodity, and by its transformation into a commodity, a thing of whatever type has been reduced to a means for its own consumption, so that 'immanent intrinsic satisfactions', (Jameson, ${ }^{15}$ p. 11) from activities are lost as everything becomes means to an end. Here, where modernism could 'critique the commodity and the effort to make it transcend itself' (Jameson ${ }^{14}$ p. 1), post-modernism is the 'consumption of sheer commodification as a process' (Jameson ${ }^{14}$ p. 1). The reach of this form of capitalism is vastly extended: it is globalised so that it reaches outwards, but it has also, crucially, moved into previously uncommodified areas including a colonisation of the unconscious, whereby everything in our social lives is penetrated by capitalism. Significantly for this current analysis, this stage of capitalism is essentially aesthetic and located within the single protean sense' (Jameson, ${ }^{15}$ p. 1) of the visual, so much so that were an ontology of this 'artificial, person-produced universe' (Jameson, ${ }^{15}$ p. 1) still possible, it would have to be an 'ontology of the visual, of being as the visible first and foremost, with the other senses draining off it; all the fights about power and desire have to take place here, between the mastery of the gaze and the illimitable richness of the visual object' 
(Jameson, ${ }^{15}$ p. 1). It is thus through the visual that post-modern capitalism is able to penetrate into the psyche, and it is the psyche that is the locus where individuals transform themselves into commodities designed for their own consumption.

\section{The contribution of examining body aesthetics to the empowerment of marketing strategies for sporting goods}

Around the world, beautiful faces and bodies sell. Advertisers and fashion houses hire good-looking people to represent their products. And, the sports industry is no different.

Few knowledgeable sports enthusiasts would deny that Joe Namath was one of the greatest quarterback to have ever played the game.

Namath's value to a football franchise was expected to extend beyond the white lines of the playing field....and it did. Coupled with his talent, Namath had looks, charisma....and wit.

At the end of the bidding wars, Namath became the highest paid football player in history - a publicity event unto itself. What many do not know, however, is that The St. Louis Cardinals football franchise (now, Phoenix Cardinals) offered Namath more money than did the New York Jets. The Jets' owner, however, assured Namath that he would make him a 'household item'.... and the image of 'Broadway Joe' was created.

At about that same time in history, beautiful scantily clad cheerleaders appeared on the sidelines of every professional team. The Dallas Cowboy Cheerleaders developed a following of their own, travelling the world as America's Ambassadors and frequently appearing in television shows and movies. Former Los Angeles Laker cheerleader, Paula Abdul used her position to open doors beyond the basketball arena... most recently, as an 'American Idol' maker.

The collegiate cheerleading ranks are filled with former gymnasts. Some, like The University of Alabama's, Sella Ward, and Princeton's, Queen Noor of Jordan, used their stints as cheerleaders (and the education they acquired while doing so) to further improve their stations in life. Queen Noor's story is a modern day example of how royalty continues to embrace athletic performers.

Hundreds of charismatic athletes and performers have parleyed their athletic and artistic abilities — and good looks - into lifestyles, which have become the envy of the world. The success of Michael Jordan, Tiger Woods and Britney Spears are just a few examples of how psychophysical aesthetics is a tangible entity, which must be recognised and embraced.

\section{The research aim and contribution of this study}

Through the study results, we aim to lead to a better understanding of the significance of others' opinions to the perceived body aesthetics. Rather than confirming body aesthetic ideals different from subculture to subculture, study respondents reframed the discussion about body aesthetics. We conclude that understanding body image concerns from the standpoint of perceived body aesthetics, rather than body aesthetics, may be a more productive and inclusive approach to the study of socially and culturally diverse young customers of sporting goods. Ultimately, it is anticipated that this will better illuminate the complex relationships among perceived influence of body aesthetics, perceived benefit of body aesthetics, perceived influence of body aesthetics to the individual, perceived influence of body aesthetics to the overall human behaviour and perceived media influence.

\section{The alternative models}

We adopt the following definition for perceived body aesthetics: 'the degree of body ideal and body dissatisfaction resulting from others' opinion'.

\section{Model 1:}

$A=f(B, G)$

where $A$ is the perceived body aesthetics; $B$ is the influence of body aesthetics to the individual; $G$ is the influence of body aesthetics to the overall human behaviour.
Research
Perceived body
Hypothesis $1\left(\mathbf{H}_{1}\right)$ : aesthetics is better predicted by model 1 . 
Model 2:

$A=f(B, H)$

where $A$ is the perceived body aesthetics; $B$ is the influence of body aesthetics to the individual; $H$ is the media influence.

\section{Research Perceived body \\ Hypothesis $2\left(\mathbf{H}_{\mathbf{2}}\right)$ : aesthetics is better predicted by model 2 .}

Model 3:

$A=f(B, G, H)$

where $A$ is the perceived body aesthetics; $B$ is the influence of body aesthetics to the individual; $G$ is the influence of body aesthetics to the overall human behaviour; $H$ is the media influence.

\section{Research Perceived body \\ Hypothesis $3\left(\mathbf{H}_{3}\right)$ : aesthetics is better predicted by model 3 .}

Model 4:

$A=f(B, E, G, H)$

where $A$ is the perceived body aesthetics; $B$ is the influence of body aesthetics to the individual; $E$ is the perceived benefit of body aesthetics; $G$ is the influence of body aesthetics to the overall human behaviour; $H$ is the media influence.

\section{Research Perceived body \\ Hypothesis $4\left(\mathbf{H}_{\mathbf{4}}\right)$ : aesthetics is better predicted by model 4 .}

\section{RESEARCH METHOD}

We address the core research themes of our study using a survey. The research hypotheses aim to test students' attitudes regarding to body aesthetics, in order to understand this modern raising issue (as an effective psychographic segmentation criterion) in the planning of modern marketing strategies of sporting goods. For this reason, we investigate the effect of some of the general behavioural descriptors regarding to social class.

\section{Participants, procedure and data collection}

The convenience sample included 401 students (interested in sporting activities) from three different Greek universities (eight departments). Our intention is to reach students with different experiences, attitudes, educational and family background. Data were collected by means of face-to-face interviews during the ten-week period.

\section{Measures}

Based on the studies such as Feingold and Mazzella, ${ }^{7}$ Brumberg $^{8}$ and Lamb et al., ${ }^{2}$ the construct of body aesthetics was measured using multiple items. All items were measured using a five-point Likert-type scale (ranging from $1=$ not at all to $5=$ very much), in order to measure students' attitudes.

With establishing content validity, the questionnaire was refined through rigorous pretesting. The pre-testing was focused on instrument clarity, question wording and validity. During the pre-testing, six students (of University of Peloponnese) were invited to comment on the questions and wordings. The comments of these six individuals then provided a basis for revisions to the measures.

\section{Testing the items}

The test of the validity of the items was based on a focus group methodology using the serial moderating technique (SMT).

Focus group methodology traditionally calls for an individual, trained moderator who personally elicits information in accord with some pre-defined purpose. The information is obtained from an assembled group, often comprised of 6-12 eligible participants. Group participants are selected to be sufficiently diverse to generate lively and innovative ideas, but sufficiently similar to bring common discourse to the session. Participants of focus groups are also expected to convene only once. Accordingly, participants are typically exposed to a single moderator or facilitator who engages one or several groups to discuss directed research topics. Since moderators vary in their training, personality and leadership 
Table 1: The items for 'body aesthetics'

\begin{tabular}{lll}
\hline Constructs & Items & Variables \\
\hline $\begin{array}{ll}\text { 1. Perceived body } \\
\text { aesthetics }(A)\end{array}$ & $\begin{array}{l}\text { Perceived influence of } \\
\text { body aesthetics to the } \\
\text { individual }\end{array}$ & (B) \\
& $\begin{array}{l}\text { Perceived benefit of body } \\
\text { aesthetics }\end{array}$ & (E) \\
& $\begin{array}{l}\text { Perceived influence of } \\
\text { body aesthetics to the } \\
\text { overall human behaviour } \\
\text { Perceived media influence }\end{array}$ & (G) \\
& & \\
\hline
\end{tabular}

styles, and interests, focus groups are open to moderator bias.

In order to test the process, we advocate several moderators in succession over two classes of the Sport Management Department of University of Peloponnese, using moderately scheduled interviews. For the opening of the interviews, we have stated the purpose. The criterion for moderator selection included the following demographic criterion: 'if students are raised to large urban centres, small towns or villages'. Previous focus group reviews (eg Tynan and Drayton $^{16}$ ) have not considered this. For many marketing research projects resting on semistructured and ill-structured problem domains that require alternative perspectives of multiple experts for both facilitating knowledge elicitation and verification, ${ }^{17}$ it would seem particularly appropriate.

For this pilot test, three moderator teams have been employed for time intervals that has been ranged from 20 to $40 \mathrm{~min}$, sufficient to cover major sections of the overall focus interview guide. This overall guide was the joint product of all participating moderators.

The above process was prerequisite, in order to secure the success of the set of interviews with students (Table 1).

\section{ANALYSES}

\section{Mean and standard deviation}

Descriptive statistics will allow describing the basic features of the data in our study. The mean or average is probably the most commonly used method of describing central tendency. The standard deviation is a more accurate and detailed estimate of dispersion because an outlier can greatly exaggerate the range. The standard deviation will allow showing the relation that set of scores has to the mean of the sample.

\section{Cronbach's alpha}

The internal consistency was measured calculating the Cronbach's alpha coefficient.

\section{Spearman rho's correlation analysis}

The research hypotheses were initially tested carrying out correlation analysis among the variables.

\section{Independent Kruskal-Wallis and Mann-Whitney tests}

The research hypothesis is validated by independent Kruskal-Wallis and Mann-Whitney tests. These nonparametric tests are done because the measured items are not normally distributed.

\section{Multiple regression analysis based on Durbin-Watson statistic and multiple $R^{2}$ coefficient}

Path analysis is the most commonly used methodology to examine the relationships among variables in the form of linear causal models. In general, the value of the path coefficient $\left(R^{2}\right)$ associated with each path represents the strength of each linear influence. The Durbin-Watson statistic examines the degree of autocorrelation, and multicolinearity was checked through correlation analysis among dependent variables, which in every case was less than 0.8 .

\section{RESEARCH RESULTS}

\section{Sample characteristics}

The response rate was 100 per cent. The participants in the study were 401 students aged 20-22 (interested in sporting activities). About 62 (61.6 per cent) were men and about 38 (38.4 per cent) were women. About 60 (59.8 per cent) came from big urban centres, about 27 (26.6 per cent) from small urban centres and about 14 (13.6 per cent) from agricultural regions. 


\section{Descriptive statistics}

Characteristics of the distributions of the answers were obtained by calculating means and standard deviations (see Table 2) for each item. The largest standard deviations $(1.38,1.36,1.30$ and 1.29) were found in relation to items $H$ and $E$. These items deal with attitudes about: (a) perceived body aesthetics and the role of media and (b) perceived benefit of body aesthetics.

\section{Comparisons among the independent groups}

Results based on Mann-Witney $U$ test, show us that there are statistical differences between men and women except of variable $E$ (see Table 3 ).

Results based on Kruskal-Wallis test, (Table 4) show us that there are statistical differences among the independent groups with different humble origins only for variables $E$ and $G$.

Results based on Kruskal-Wallis test (Table 5) show us that there are no statistical differences among the independent groups with different parents' educational background.

\section{Findings of the survey}

The measured items are presented in Table 6 .

\section{Interpretation of the questionnaire results}

Based on the questionnaire results and without combining the questions with each other, we can interpret the responses as follows.

Not surprisingly, about 90-95 per cent of the respondents seems to care about their body aesthetics and seriously interested in what other people think about their body. Such a finding indicates how crucial the issue of body aesthetics is for young people.

Another interesting finding is that body aesthetics is considered as a source of success for the $1 / 3$ of the respondents. Such a finding could interpret the logic of many positioning

Table 2: Descriptive statistics and internal consistency reliability

\begin{tabular}{llllll}
\hline Body aesthetics & & & & & $\begin{array}{c}\text { Cronbach's } \\
\text { alpha 0.70 }\end{array}$ \\
\hline Variables & N & Minimum & Maximum & Mean & Std. Deviation \\
\hline$A$ & 400 & 1 & 5 & 3.07 & 1.108 \\
$B$ & 401 & 1 & 5 & 3.57 & 1.091 \\
$E$ & 399 & 1 & 5 & 2.11 & 1.266 \\
$G$ & 401 & 1 & 5 & 3.18 & 1.228 \\
$H$ & 401 & 1 & 5 & 2.85 & 1.304 \\
Valid $N$ (listwise) & 388 & & & & \\
\hline
\end{tabular}

Table 3: Mann-Witney $U$ test 1 (Grouping variable: sex)

\begin{tabular}{lrrrrr}
\hline & A & B & E & G & H \\
\hline Mann-Whitney U & $15,785.000$ & $14,032.500$ & $17,011.000$ & $14,816.000$ & $11,439.500$ \\
Wilcoxon W & $27,566.000$ & $25,813.500$ & $46,901.000$ & $26,597.000$ & $23,220.500$ \\
Z & -2.686 & -4.399 & -1.478 & -3.615 & -6.692 \\
Asymp. Sig. (2-tailed) & 0.007 & 0.000 & 0.139 & 0.000 & 0.000 \\
\hline
\end{tabular}

Table 4: Kruskal-Wallis test 1 (Grouping variable: humble origin)

\begin{tabular}{|c|c|c|c|c|c|}
\hline & A & B & $\mathbf{E}$ & $\mathbf{G}$ & $\mathbf{H}$ \\
\hline $\begin{array}{l}\chi^{2} \\
\text { d.f. } \\
\text { Asymp. Sig. }\end{array}$ & $\begin{array}{l}2.246 \\
2 \\
0.325\end{array}$ & $\begin{array}{l}4.879 \\
2 \\
0.087\end{array}$ & $\begin{array}{l}6.058 \\
2 \\
0.048\end{array}$ & $\begin{array}{l}15.331 \\
2 \\
0.000\end{array}$ & $\begin{array}{l}2.378 \\
2 \\
0.305\end{array}$ \\
\hline
\end{tabular}


Table 5: Kruskal-Wallis test 2 (Grouping variable: parents' educational background)

\begin{tabular}{llllll}
\hline & A & B & E & G & H \\
\hline$\chi^{2}$ & 1.511 & 3.761 & 2.239 & 0.620 & 1.602 \\
df & 2 & 2 & 2 & 2 & 2 \\
Asymp. Sig. & 0.470 & 0.153 & 0.326 & 0.733 & 0.449 \\
\hline
\end{tabular}

Parents' educational background

Table 6: Frequencies of measured items

\begin{tabular}{|c|c|c|c|c|c|}
\hline & & Frequency & Percent & Valid percent & $\begin{array}{l}\text { Cumulative } \\
\text { percent }\end{array}$ \\
\hline \multicolumn{6}{|c|}{ Question $1(A)$ : 'Do you care what others think about your body?' } \\
\hline \multirow[t]{6}{*}{ Valid } & not at all & 38 & 9.5 & 9.5 & 9.5 \\
\hline & a little bit & 78 & 19.5 & 19.5 & 29.0 \\
\hline & somehow & 142 & 35.4 & 35.5 & 64.5 \\
\hline & a lot & 102 & 25.4 & 25.5 & 90.0 \\
\hline & very much & 40 & 10.0 & 10.0 & 100.0 \\
\hline & Total & 400 & 99.8 & 100.0 & \\
\hline Missing & System & 1 & 0.2 & & \\
\hline Total & & 401 & 100.0 & & \\
\hline \multicolumn{6}{|c|}{ Question 2 (B): 'Do you care about your body aesthetics?' } \\
\hline \multirow[t]{6}{*}{ Valid } & not at all & 20 & 5.0 & 5.0 & 5.0 \\
\hline & a little bit & 47 & 11.7 & 11.7 & 16.7 \\
\hline & somehow & 100 & 24.9 & 24.9 & 41.6 \\
\hline & a lot & 152 & 37.9 & 37.9 & 79.6 \\
\hline & very much & 82 & 20.4 & 20.4 & 100.0 \\
\hline & Total & 401 & 100.0 & 100.0 & \\
\hline \multicolumn{6}{|c|}{ Question $3(E)$ : 'Do you believe that body aesthetics is a source of success?' } \\
\hline \multirow[t]{6}{*}{ Valid } & not at all & 190 & 47.4 & 47.6 & 47.6 \\
\hline & a little bit & 60 & 15.0 & 15.0 & 62.7 \\
\hline & somehow & 86 & 21.4 & 21.6 & 84.2 \\
\hline & a lot & 40 & 10.0 & 10.0 & 94.2 \\
\hline & very much & 23 & 5.7 & 5.8 & 100.0 \\
\hline & Total & 399 & 99.5 & 100.0 & \\
\hline Missing & System & 2 & 0.5 & & \\
\hline Total & & 401 & 100.0 & & \\
\hline \multicolumn{6}{|c|}{ Question 4 (G): 'Do you believe that body aesthetics determine human behaviour?' } \\
\hline \multirow[t]{6}{*}{ Valid } & not at all & 45 & 11.2 & 11.2 & 11.2 \\
\hline & a little bit & 78 & 19.5 & 19.5 & 30.7 \\
\hline & somehow & 97 & 24.2 & 24.2 & 54.9 \\
\hline & a lot & 122 & 30.4 & 30.4 & 85.3 \\
\hline & very much & 59 & 14.7 & 14.7 & 100.0 \\
\hline & Total & 401 & 100.0 & 100.0 & \\
\hline \multicolumn{6}{|c|}{ Question $5(H)$ : 'Do you care about the body ideal that media communicate?' } \\
\hline \multirow[t]{6}{*}{ Valid } & not at all & 78 & 19.5 & 19.5 & 19.5 \\
\hline & a little bit & 90 & 22.4 & 22.4 & 41.9 \\
\hline & somehow & 101 & 25.2 & 25.2 & 67.1 \\
\hline & a lot & 80 & 20.0 & 20.0 & 87.0 \\
\hline & very much & 52 & 13.0 & 13.0 & 100.0 \\
\hline & Total & 401 & 100.0 & 100.0 & \\
\hline
\end{tabular}

strategies that sporting goods organisations have adopted.

Quite surprising seems to be the answers of the respondents at the last two questions, where about 70 per cent believe that body aesthetics impacts significantly human behaviour and about 60 per cent really care about the body ideal that media communicate. The last two questions show 
Table 7: Correlation analyses $(n=401)$

\begin{tabular}{|c|c|c|c|c|c|c|c|c|c|}
\hline Variables & 1 & 2 & 3 & 4 & 5 & 6 & 7 & 8 & 9 \\
\hline 1. & 1.000 & $0.594^{*}$ & $0.315^{\star}$ & $0.169^{\star}$ & $0.255^{\star}$ & 0.049 & $0.334^{*}$ & $0.349^{\star}$ & $0.145^{\star}$ \\
\hline 2. & $0.594^{*}$ & 1.000 & $0.339^{\star}$ & $0.130^{*}$ & $0.155^{\star}$ & 0.117 & $0.355^{\star}$ & $0.318^{*}$ & 0.031 \\
\hline 3. & $0.315^{\star}$ & $0.339^{*}$ & 1.000 & $0.607^{*}$ & $0.329^{*}$ & 0.077 & $0.184^{*}$ & $0.251^{*}$ & $0.163^{\star}$ \\
\hline 4. & $0.169^{\star}$ & $0.130^{*}$ & $0.607^{*}$ & 1.000 & $0.318^{*}$ & $0.182^{*}$ & 0.086 & 0.074 & $0.238^{\star}$ \\
\hline 5. & $0.255^{\star}$ & $0.155^{\star}$ & $0.329^{*}$ & $0.318^{*}$ & 1.000 & 0.071 & $0.265^{\star}$ & $0.217^{*}$ & $0.220^{*}$ \\
\hline 6. & 0.049 & $0.117^{*}$ & 0.077 & $0.182^{*}$ & 0.071 & 1.000 & $0.211^{*}$ & 0.125 & 0.121 \\
\hline 8. & $0.349^{*}$ & $0.318^{*}$ & $0.251^{*}$ & 0.074 & $0.217^{*}$ & 0.125 & $0.313^{*}$ & 1.000 & $0.344^{\star}$ \\
\hline 9. & $0.145^{\star}$ & 0.031 & $0.163^{*}$ & $0.238^{*}$ & $0.220^{*}$ & 0.121 & $0.269^{*}$ & $0.344^{*}$ & 1.000 \\
\hline
\end{tabular}

*Spearman's rho,correlation is significant at the 0.01 level (2-tailed)

us how the effect of technological determinism becomes stronger (see theory of technological determinism: "human behaviour is directly associated with the evolution of technologies').

\section{Correlations and path analyses}

The Spearman's rho correlation coefficients among the variables indicate that all variables are significantly correlated (Table 7).

Path analysis was carried out to test the research hypotheses, since it is the most commonly used multivariate analytical methodology for empirically examining sets of relationships in the form of linear causal models. Multicollinearity on multiple linear regression can be controlled in two ways: (1) correlation between independent variables should all be less than $0.8 ;(2)$ variance inflation factors (VIF) should be less than 10 . In our study, multicollinearity was not an issue because the correlations between independent variables were all less than 0.8 and the VIFs were all less than 10 . Autocorrelation on multiple linear regression can be controlled by Durbin-Watson statistic, where a value close to 2 indicates nonautocorrelation a value towards 0 indicates positive autocorrelation, and a value towards 4 indicates negative autocorrelation. In almost all path relations tests, Durbin-Watson statistic ranged between 1.62 and 1.96 indicating that autocorrelation should not be considered as an issue (Tables 8 and 9).

\section{DISCUSSION}

Through the study results, we aimed to lead to a better understanding of the significance of others' opinions to the perceived body aesthetics.
According to the research results, we accept the fourth hypothesis $\left(\mathrm{H}_{4}\right)$, which means that model 4 better predicts perceived body aesthetics.

According to the findings of the literature review presented in the beginning of this study, it seems that it has been widely hypothesised that ethnically based differences in aesthetic body ideals mitigate cultural pressures that contribute to body disparagement.

According to the findings of our study, it seems that perceived body aesthetics linked to some of the general behavioural descriptor of social class should be considered as a valuable segmentation criterion. The findings of our study showed us the statistical differences between men and women, which indicate different set of attitudes regarding to body aesthetics (sex criterion). Another important finding indicates that there are statistical differences among the respondents from different regions (humble origin criterion), which indicate the importance of examining subcultural diversification as presented in the Introduction.

Rather than confirming body aesthetic ideals different among cultures, our study respondents reframed the discussion about body aesthetics. We conclude that understanding body image concerns from the standpoint of perceived body aesthetics, rather than body aesthetics, may be a more productive and inclusive approach to the study of socially and culturally diverse young customers of sporting goods. Ultimately, it is anticipated that this will better illuminate the complex relationships among perceived influence of body aesthetics, perceived benefit of body aesthetics, perceived influence of body aesthetics to the 
Table 8: Regression results of predicted path relationships $(n=401)$

\begin{tabular}{|c|c|c|c|c|c|c|c|}
\hline Dependent variable & $\begin{array}{l}\text { Independent } \\
\text { variables }\end{array}$ & $t$ & $\hat{a}$ & $\begin{array}{l}\text { Durbin- } \\
\text { Watson }\end{array}$ & $R^{2}$ & $P$ & $\begin{array}{l}\text { Comment } \\
\text { (support) }\end{array}$ \\
\hline \multicolumn{8}{|l|}{ Model 1} \\
\hline $\begin{array}{l}\mathbf{H}_{1} \text { : Significance of others' } \\
\text { opinions }\end{array}$ & $\begin{array}{l}\text { Perceived influence } \\
\text { of body aesthetics }\end{array}$ & 5.781 & 0.872 & 1.915 & 0.368 & 0.000 & Medium \\
\hline $\begin{array}{l}\text { Significance of } \\
\text { others' opinions }\end{array}$ & $\begin{array}{l}\text { Perceived influence } \\
\text { of body aesthetics } \\
\text { to human behaviour }\end{array}$ & 14.410 & 2.084 & 1.809 & 0.118 & 0.000 & Medium \\
\hline $\begin{array}{l}\text { Significance of } \\
\text { others' opinions }\end{array}$ & All above & 3.922 & 0.639 & 1.870 & 0.387 & 0.000 & Medium \\
\hline \multicolumn{8}{|l|}{ Model 2} \\
\hline $\begin{array}{l}\mathbf{H}_{\mathbf{2}} \text { : Significance of others' } \\
\text { opinions }\end{array}$ & $\begin{array}{l}\text { Perceived influence } \\
\text { of body aesthetics }\end{array}$ & 5.781 & 0.872 & 1.915 & 0.368 & 0.000 & Medium \\
\hline $\begin{array}{l}\text { Significance of } \\
\text { others' opinions }\end{array}$ & $\begin{array}{l}\text { Perceived influence } \\
\text { of media }\end{array}$ & 17.977 & 2.252 & 1.971 & 0.115 & 0.000 & Medium \\
\hline $\begin{array}{l}\text { Significance of } \\
\text { others' opinions }\end{array}$ & All above & 4.124 & .649 & 1.977 & 0.394 & 0.000 & Medium \\
\hline \multicolumn{8}{|l|}{ Model 3} \\
\hline $\begin{array}{l}\mathbf{H}_{3} \text { : Significance of others' } \\
\text { opinions }\end{array}$ & $\begin{array}{l}\text { Perceived influence } \\
\text { of body aesthetics }\end{array}$ & 5.781 & 0.872 & 1.915 & 0.368 & 0.000 & Medium \\
\hline $\begin{array}{l}\text { Significance of } \\
\text { others' opinions }\end{array}$ & $\begin{array}{l}\text { Perceived influence } \\
\text { of body aesthetics } \\
\text { to human behaviour }\end{array}$ & 14.410 & 2.084 & 1.809 & 0.118 & 0.000 & Medium \\
\hline $\begin{array}{l}\text { Significance of } \\
\text { others' opinions }\end{array}$ & $\begin{array}{l}\text { Perceived influence } \\
\text { of media }\end{array}$ & 17.977 & 2.252 & 1.971 & 0.115 & 0.000 & Medium \\
\hline $\begin{array}{l}\text { Significance of } \\
\text { others' opinions }\end{array}$ & All above & 3.055 & 0.506 & 1.931 & 0.405 & 0.002 & Strong \\
\hline \multicolumn{8}{|l|}{ Model 4} \\
\hline $\begin{array}{l}\mathbf{H}_{4} \text { : Significance of others' } \\
\text { opinions }\end{array}$ & $\begin{array}{l}\text { Perceived influence } \\
\text { of body aesthetics }\end{array}$ & 5.781 & 0.872 & 1.915 & 0.368 & 0.000 & Medium \\
\hline $\begin{array}{l}\text { Significance of } \\
\text { others' opinions }\end{array}$ & $\begin{array}{l}\text { Perceived benefit of } \\
\text { body aesthetics }\end{array}$ & 24.789 & 2.569 & 1.854 & 0.076 & 0.000 & Low \\
\hline $\begin{array}{l}\text { Significance of } \\
\text { others' opinions }\end{array}$ & $\begin{array}{l}\text { Perceived influence } \\
\text { of body aesthetics } \\
\text { to human behaviour }\end{array}$ & 14.410 & 2.084 & 1.809 & 0.118 & 0.000 & Medium \\
\hline $\begin{array}{l}\text { Significance of } \\
\text { others' opinions }\end{array}$ & $\begin{array}{l}\text { Perceived influence } \\
\text { of media }\end{array}$ & 17.977 & 2.252 & 1.971 & 0.115 & 0.000 & Medium \\
\hline $\begin{array}{l}\text { Significance of } \\
\text { others' opinions }\end{array}$ & All above & 2.423 & .405 & 1.977 & 0.420 & 0.016 & Strong \\
\hline
\end{tabular}

individual, perceived influence of body aesthetics to the overall human behaviour and perceived media influence.

It seems though, body aesthetics is also defined by cultural constructs that have changed throughout time. Ideal beauty varies in different societies around the world. Western culture at this time has embraced the fashion model as an exemplar - greatly because we are constantly inundated with these images that are ironically far from the norm. We find beauty in familiar physical traits, particularly those images portrayed in the media. Just looking at a fashion magazine tends to leave men and women less satisfied with their weight and size.
The research themes and findings of this study allowed us to outline the following significant implications for marketing managers and for policy-makers.

\section{Implications for sports marketing managers}

The body has always been a central object in many scientific disciplines, but in the wake of a recent scholarship on gender the body has come into focus as never before in the history. Many studies demonstrate how the body has been used as a 'natural' argument for definitions and evaluations of femininity and masculinity, as well as how these cultural constructions imply value 
Table 9: Research results

\begin{tabular}{|c|c|c|}
\hline Hypothesis & & Support \\
\hline $\mathrm{H}_{1}$ & $\begin{array}{c}\mathbf{H}_{1}=\text { Significance of others' } \\
\text { opinions about our body } \\
\text { aesthetics is better } \\
\text { predicted by Model } 1 .\end{array}$ & Supported \\
\hline $\mathrm{H}_{2}$ & $\begin{aligned} \mathbf{H}_{2}= & \text { Significance of others' } \\
& \text { opinions about our body } \\
& \text { aesthetics is better } \\
& \text { predicted by Model } 2 .\end{aligned}$ & Supported \\
\hline $\mathrm{H}_{3}$ & $\begin{aligned} \mathbf{H}_{3}= & \text { Significance of others' } \\
& \text { opinions about our body } \\
& \text { aesthetics is better } \\
& \text { predicted by Model } 3 .\end{aligned}$ & Supported \\
\hline $\mathrm{H}_{4}$ & $\begin{aligned} \mathbf{H}_{4}= & \text { Significance of others' } \\
& \text { opinions about our body } \\
& \text { aesthetics is better } \\
& \text { predicted by Model } 4 .\end{aligned}$ & $\begin{array}{l}\text { Strongly } \\
\text { supported }\end{array}$ \\
\hline
\end{tabular}

hierarchies and power relationships. Art and literature often deal with tensions between the body as experience and the meanings into which it is inscribed.

The goal of this study is to elucidate and interrogate theoretical scholarship on the perceived body aesthetics and provide inspiration for future research from marketing scholars.

The body is intimately connected with an aesthetic approach to 'the other'. That the body is discursive is reflected in a variety of different contexts, such as culturally conditioned illnesses, contemporary fashions, youth culture, and plastic and performative arts. The discourses of the body must also be seen both as a commercial phenomenon.

Regarding the implications for marketing strategies of sporting goods, our study indicate the raising importance of studying perceived body aesthetics, in order to describe the market's benefit segments (eg self-oriented, tough customers, young urban trendsetters, blue collars, mature conformists, etc).

Our study underline the raising issue of perceived body aesthetics, as a market segmentation criterion segmenting the markets of sporting goods into a series of groups according to the perceived benefits and beliefs.

Marketing managers must clearly understand that however large the organisation, its resources are usually limited compared to the number of alternative marketing investments available. Thus, any organisation must make choices. For a given market, the marketing investment options are expressed in terms of market segments. Even in the unusual case where an organisation can afford to serve all market segments, it must determine the most appropriate allocation of its marketing effort across segments.

Model 4 can provide a better understanding of the significance of others' opinions to the perceived body aesthetics, in terms of a primary basis for behaviour analysis in the markets of sporting goods. Marketing managers must seriously consider that understanding body image concerns from the standpoint of perceived body aesthetics, rather than body aesthetics, may be a more productive and inclusive approach to the study of socially and culturally diverse young customers of sporting goods. Ultimately, it is anticipated that this will better illuminate the complex relationships among perceived influence of body aesthetics, perceived benefit of body aesthetics, perceived influence of body aesthetics to the individual, perceived influence of body aesthetics to the overall human behaviour and perceived media influence.

\section{Implications for policy-makers}

While a beautiful face and body, a gold medal, a bronze star, a championship ring or green jacket will get the attention of the world's 'star-makers', these and related favours, should be viewed only as a springboard. The ability to speak intelligently, exercise good manners and transition the competitive edge, learned in the athletic arena, into systems, which win in the business world is what separates the enduring 'super-stars' from the flash is the pan. And, as it has been since history was recorded, the fittest, wisest and most attractive among the competitors are granted favours and a better chance to prosper.

With opportunity comes responsibility. So, it becomes the duty of the society and the organisations to prepare citizens/clients physically, mentally, socially and spiritually for the challenges they are sure to face. Coaches and teachers are charged with the responsibility to teach the 
mechanics of competitive sports...and, to instill a heightened level of awareness regarding how students/clients should 'package' themselves so that opportunity seeks them out. In the 'imagebuilding' industry, everyone has a chance to excel. The better 'image-builders' are also in high demand. The ideal 'competitive package' includes tools, which allow one to compete. Such a 'package' should include instruction on how to prevent disease and keep the body functioning at a high level...for years to come. And, early intervention seems to be crucial. Perhaps, school officials and parent-teachers organisations should include physical and health education as part of preparing one to live a healthier, productive life.

Obesity is the fastest growing preventable 'disease' in the United States... and children are the fastest growing segment of this emerging obese population. Obesity is also a major contributor to life-threatening conditions, such as high blood pressure, diabetes, arthritis, heart disease and depression - all of which shorten one's years of productive life.

\section{Limitations}

This study has the following important limitation. The present study involves the use of a convenience sample. It seems unlikely that either of our sample is representative of university students. Although it would be desirable for future researchers to use more representative samples, this is probably not as serious a limitation as it may appear. Institutions of higher education may vary greatly within a country, but the influences of the media appear to be ubiquitous. There is compelling evidence that the thin body ideal, high body dissatisfaction and disordered eating are part of the process of globalisation that now touches most cultures and most nations (eg Becker et al., ${ }^{18}$ Gordon, ${ }^{19}$ Nasser et al. ${ }^{20}$ ). When the global village watches the same television portrayals of feminine beauty, and when young women around the world are exposed to the same or very similar images in fashion magazines, most young people, at least in the context of the variables in the present study, arguably belong to very similar populations.

\section{CONCLUSION}

According to the research results, we accept the fourth hypothesis $\left(\mathrm{H}_{4}\right)$, which means that model 4 better predicts perceived body aesthetics.

It seems that body dissatisfaction is of a high important social issue because of its established association with depression, low self-esteem and disordered eating. So, that is why implications of this study for policy-makers should be seriously considered.

On the other hand, body aesthetics is an issue of high importance not only for the imagemaking industry but also for many businesses as a very attractive market (food industry, fashion industry, beauty industry and advertising industry). Around the world, beautiful faces and bodies sell. Advertisers and fashion houses hire good-looking people to represent their products. And, the sports industry is no different.

Through the study results we aimed to lead to a better understanding of the significance of others' opinions to the perceived body aesthetics. The multiple linear regression method was used to model the relationship among influence of body aesthetics, perceived benefit of body aesthetics and influence of media to perceived body aesthetics. Four alternative models were developed in order to lead to a better understanding of the significance of others' opinions to the perceived body aesthetics. We addressed the core research themes of our study using a survey. The research hypotheses aimed to test students' attitudes regarding to body aesthetics, in order to understand this modern raising issue (as an effective psychographic segmentation criterion) in the planning of modern marketing strategies of sporting goods. For this reason, we investigate the effect of some of the general behavioural descriptors regarding to social class. The convenience sample included 401 students, interested in sporting activities.

Hundreds of charismatic athletes and performers have parleyed their athletic and artistic abilities - and good looks - into lifestyles, which have become the envy of the world. The success of a series of sport celebrities (such as Jordan, Zidane, etc) is just a few examples 
of how psychophysical aesthetics is a tangible entity, which must be recognised and embraced.

Ending, as technological determinism effect becomes stronger (see media technologies globalisation) the degree of body ideal and body dissatisfaction resulting from others' opinion, will be much stronger and will be directly associated with the technology determinism effect. In terms of a marketing strategy formulation, this means that we are in front of a very effective psychographic criterion that will empower significantly the customer value and will drive to a more efficient management of the segmentation process.

\section{References}

1 Silverstein, B. and Perlik, D. (1995) 'The Cost of Competence: Why Inequality Causes Depression, Eating Disorders, and Illness in Women', Oxford University, New York.

2 Lamb, C. S., Jackson, L. A., Cassiday, P. B. and Priest, D. J. (1993) 'Body figure preferences of men and women: A comparison of two generations', Sex Roles, Vol. 28, pp. 345-358.

3 Garner, D. M., Garfinkel, P. E., Schwartz, D. and Thompson, M. (1980) 'Cultural expectations of thinness in women', Psychological Reports, Vol. 47, pp. 483-491.

4 Morris, A., Cooper, T. and Cooper, P. J. (1989) 'The changing shape of female fashion models', International Journal of Eating Disorders, Vol. 8, pp. 593-596.

5 Wiseman, C. V., Gray, J. J., Mosimann, J. E. and Ahrens, A. H. (1992) 'Cultural expectations of thinness in women: An update', International Journal of Eating Disorders, Vol. 11, pp. 85-89.

6 Rodin, J., Silberstein, L. R. and Striegel-Moore, R. H. (1984) 'Women and weight: A normative discontent', in Sonderegger, T. B. (ed) 'Nebraska Symposium on Motivation', University of Nebraska Press, Lincoln.
7 Feingold, A. and Mazzella, R. (1998) 'Gender differences in body image are increasing', Psychological Science, Vol. 9, pp. $190-198$.

8 Brumberg, J. J. (1997) 'The Body Project: An Intimate History of American Girls', Random House, New York.

9 Catina, A., Boyadjieva, S. and Bergner, M. (1996) 'Social context, gender identity and eating disorders in Western and Eastern Europe: Preliminary results of a comparative study', European Eating Disorders Review, Vol. 4, pp. 100-106.

10 Catina, A. and Joja, O. (2001) 'Emerging markets: Submerging women', in Nasser, M., Katzman, M.A. and Gordon, R.A. (eds) 'Eating Disorders and Cultures in Transitions', Taylor \& Francis, New York.

11 Bilukha, O. O. and Utermohlen, V. (2002) 'Internalization of Western standards of appearance, body dissatisfaction and dieting in urban educated Ukrainian females', European Eating Disorders Review, Vol. 10, pp. 120-137.

12 Papezova, H. (2002) 'Eating disorders across Europe: History of services for eating disorders with regard to political and women's situational changes in the Czech Republic', European Eating Disorders Review, Vol. 10, pp. 79-84.

13 Rathner, G. (2001) 'Post-communism and the marketing of the thin ideal', in Nasser, M., Katzman, M. A., Gordon R. A. (eds) 'Eating Disorders and Cultures in Transitions', Taylor \& Francis, New York.

14 Jameson, F. (1991) 'Postmodemism, or, the Cultural Logic of Late Capitalism', Verso, London.

15 Jameson, F. (1992) 'Signatures of the Visible', Routledge, London.

16 Tynan, C. A. and Drayton, J. L. (1988) 'Conducting focus groups - A guide for first time users', Marketing Intelligence and Planning, Vol. 6, No. 1, pp. 5-9.

17 Grabowski, M., Massey, A. P. and Wallace, W. A. (1992) 'Focus groups as a group knowledge acquisition technique', Knowledge Acquisition, Vol. 4, pp. 407-425.

18 Becker, A. E., Burwell, R. A., Gilman, S. E., Herzog, D. B. and Hamburg, P. (2002) 'Eating behaviours and attitudes following prolonged exposure to television among ethnic Fijian adolescent girls', British Journal of Psychiatry, Vol. 180, pp. 509-514.

19 Gordon, R. A. (2000) 'Eating Disorders: Anatomy of a Social Epidemic', 2nd edn, Blackwell, Oxford.

20 Nasser, M., Katzman, M. A. and Gordon, R. A. (2001) 'Eating Disorders and Cultures in Transitions', Taylor \& Francis, New York. 